\title{
Klaus G. Beuckers, Beate Johlen-Budnik (dir.), Das \\ Gerresheimer Evangeliar. Eine spätottonische Prachthandschrift als Geschichtsquelle
}

Felix Schaefer

\section{OpenEdition}

Édition électronique

URL : http://journals.openedition.org/ifha/8849

DOI : $10.4000 /$ ifha. 8849

ISSN : 2198-8943

\section{Éditeur}

IFRA - Institut franco-allemand (sciences historiques et sociales)

\section{Référence électronique}

Felix Schaefer, « Klaus G. Beuckers, Beate Johlen-Budnik (dir.), Das Gerresheimer Evangeliar. Eine spätottonische Prachthandschrift als Geschichtsquelle », Revue de l'IFHA [En ligne], Date de recension, mis en ligne le 02 novembre 2017, consulté le 25 septembre 2020. URL : http:// journals.openedition.org/ifha/8849; DOI : https://doi.org/10.4000/ifha.8849

Ce document a été généré automatiquement le 25 septembre 2020.

(CIFHA 


\title{
Klaus G. Beuckers, Beate Johlen- Budnik (dir.), Das Gerresheimer Evangeliar. Eine spätottonische Prachthandschrift als Geschichtsquelle
}

\author{
Felix Schaefer
}

\section{RÉFÉRENCE}

Klaus G. Beuckers, Beate Johlen-Budnik (dir.), Das Gerresheimer Evangeliar. Eine spätottonische Prachthandschrift als Geschichtsquelle, Wien, Köln, Weimar: Böhlau (Forschungen zu Kunst, Geschichte und Literatur des Mittelalters 1), 2016, 232 p., 128 ill., $50 €$

Ce riche volume est consacré à un évangéliaire ottonien conçu pour l'abbaye SaintHippolyte de Gerresheim qui fait aujourd'hui partie du trésor de l'église paroissiale Sainte-Marguerite. Faisant suite au colloque organisé en 2015 à Gerresheim par Klaus Gereon Beuckers et Beate Johlen-Budnik, il présente l'état des recherches sur ce codex et l'étudie sous les angles paléographique, codicologique, artistique, politique et praxéologique.

K. Gereon Beuckers discute d'abord l'historiographie depuis la fin du XIX ${ }^{\mathrm{e}}$ siècle, en insistant notamment sur les problèmes de datation et sur les relations du manuscrit avec d'autres évangéliaires carolingiens ou de l'école de Cologne. Il évoque aussi l'identité encore mystérieuse de la pia Hidda, donatrice qui a inscrit son nom dans le manuscrit. Doris Oltrogge livre une description codicologique du manuscrit et formule des hypothèses prudentes sur sa planification et sur la coopération entre copistes qu'illustrent les esquisses et les travaux préparatoires présentés en annexe. D. Oltrogge reconnaît dans les utilisations postérieures l'expression d'une identité locale, mais non figée, intégrant par exemple le souvenir de l'abbesse Theophanu, dont une donation a été inscrite au XI ${ }^{\mathrm{e}}$ siècle sur un feuillet vierge. Annemarie Stauffer montre que la 
décoration a été protégée au $\mathrm{XV}^{\mathrm{e}}$ siècle, alors que l'on ajoutait au manuscrit de précieux marque-pages. Hans-Walter Stork propose une étude paléographique et identifie un scribe secondaire dans l'Évangile de Luc, ainsi qu'une main un peu postérieure, qui a terminé le sommaire des Évangiles. Il date la main principale des années 1020-1040, et la localise avec vraisemblance à Saint-Géréon de Cologne.

Cet évangéliaire ne concerne pas seulement l'époque ottonienne. Une série d'articles sont ainsi consacrés à des ajouts s'étalant entre le $\mathrm{XI}^{\mathrm{e}}$ et le XVIII ${ }^{\mathrm{e}}$ siècle. Jens Lieven explique la donation de l'abbesse Theophanu au milieu du XI ${ }^{\mathrm{e}}$ siècle, ajoutée dans le manuscrit au tournant du XII ${ }^{e}$ siècle, d'une part par le contexte historique de l'abbaye, qui, détruite par les Hongrois, était sous la protection des archevêques de Cologne et sous l'influence des Ezzonides, d'autre part par l'abbatiat de Theophanu, qui semble avoir voulu assurer sa propre mémoire liturgique. Plusieurs ajouts sont décrits par Andreas Bihrer : le serment de l'abbesse Rikardis de Schleiden et deux inventaires de trésors du XIX ${ }^{e}$ siècle. A. Bihrer corrige quelques datations erronées et reconstitue à l'aide de ces textes l'usage local du manuscrit, qui joua pour l'abbaye un rôle non seulement liturgique, mais aussi symbolique, étant utilisé pour les serments et pour la sacristie. La plupart des ajouts faits jusqu'au XVII ${ }^{\mathrm{e}}$ siècle sont transcrits, traduits et brièvement commentés par Philipp Frey et Friederike Szill. Enfin, Thorsten Henke étudie le cas d'un autre évangéliaire devenu véhicule identitaire à l'époque moderne et associé à Gandersheim : y sont également inscrits plusieurs serments, avec des souscriptions du chapitre canonial datant du XVII ${ }^{\mathrm{e}}$ siècle.

Les deux dernières contributions replacent le manuscrit dans son contexte moderne. Julia von Ditfurth se penche sur le dossier d'une visite archiépiscopale en 1669, qui prescrivit de mettre par écrit une partie des serments du manuscrit et d'adapter l'église au style baroque. Beate Johlen-Budnik conclut le volume sur le XIX ${ }^{e}$ siècle en exposant comment le manuscrit perdit sa fonction juridique et idéelle lors de la sécularisation du couvent. La reliure baroque en argent fut vendue alors que le manuscrit éveillait l'intérêt des collectionneurs romantiques : en 1875, il entra en possession de CharlesAntoine de Hohenzollern-Sigmaringen, qui le fit relier, avant d'entrer, sur l'intervention des autorités, à l'église Sainte-Marguerite. La richesse du matériel de ce volume est exceptionnelle. Les 99 reproductions en couleurs n'embrassent certes pas le codex entier (disponible sur le site du projet Codices Electronici Ecclesiae Coloniensis), mais tous les feuillets comportant des éléments décoratifs ou mentionnés par les auteurs. L'annexe contient des détails très riches, notamment des croquis derrière les enluminures, rendus visibles par ultraviolet. Un regret : il manque des index, et on se demande s'il n'aurait pas été possible d'éviter quelques chevauchements, répétitions et références croisées entre les contributions. Mais ce recueil offre aux historiens et aux historiens de l'art tant médiévistes que modernistes un matériel précieux, à la croisée des disciplines. Le manuscrit liturgique est ici envisagé dans une perspective totale et transhistorique - une méthode trop rarement mise en œuvre et menée de façon exemplaire dans ce volume. 
INDEX

Index chronologique : Moyen Âge

Thèmes : Histoire religieuse, Histoire de l'art

\section{AUTEURS}

FELIX SCHAEFER

Université de Tübingen 